\title{
Combination of enabling technologies to improve and describe the stereoselectivity of Wolff-Staudinger cascade reaction
}

\author{
B. Musio ${ }^{a}$ \\ F. Mariani ${ }^{a, b}$ \\ E. P. Śliwiński \\ M. A. Kabeshov \\ H. Odajimac \\ S. V. Ley*a, \\ ${ }^{a}$ University of Cambridge, Department of Chemistry, Lensfield \\ Road, Cambridge, CB2 1EW United Kingdom \\ b Universitat de Barcelona, Laboratori de Química \\ Orgànica,Facultat de Farmàcia, Av. Joan XXIII s/n, 08028 \\ Barcelona, Spain \\ Saida FDS, 143-10 Itsushiki, Yaizu-shi, Shizuoka-prefecture \\ 4250054 - Japan \\ svl1000@cam.ac.uk
}

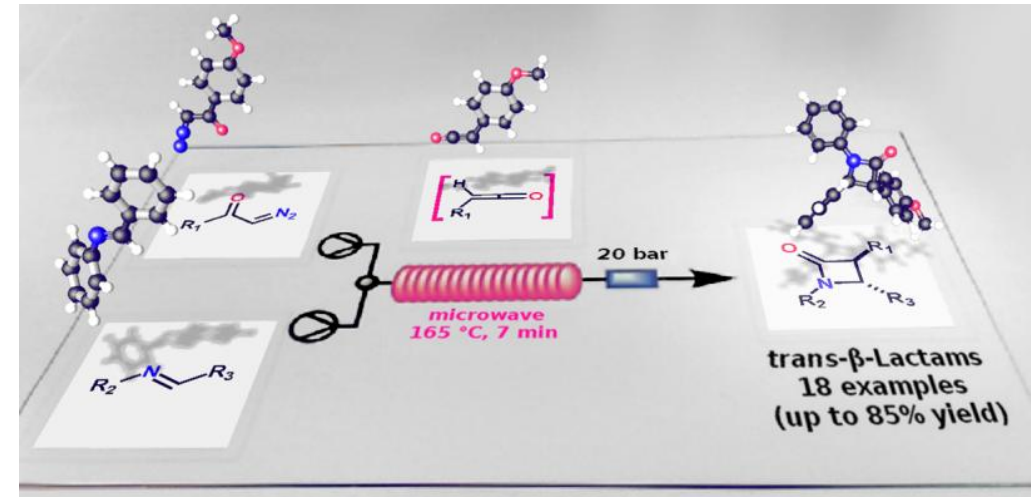

\begin{abstract}
Received:
Pub
DOI:

Abstract A new single-mode bench-top resonator was evaluated for the microwave-assisted flow generation of primary ketenes by thermal decomposition of $\alpha$-diazoketones at high temperature. A number of amides and $\beta$-lactams were obtained by in situ ketene generation and reaction with amines and imines respectively in good to excellent yields. The preferential formation of trans-configured $\beta$-lactams was observed during the $[2+2]$ Staudinger cycloaddition of a range of ketenes with different imines under controlled reaction conditions. Some insights into the mechanism of this reaction at high temperature are reported and a new web-based molecular viewer, which takes advantage from augmented reality (AR) technology, is also described for a faster interpretation of computed data.
\end{abstract}

Key words microwave $\bullet$ Wolff $\bullet$ Staudinger $\bullet$ flow $\bullet$ Augmented Reality

We wish to report a new multidisciplinary approach to solve a chemical synthesis problem using a combined armory of some new enabling technologies to achieve sustained high temperature processes with improved reaction selectivity, which can be mechanistically rationalized through computational methods and finally visualized by a new webbased molecular viewer employing augmented reality (AR) technology. While most publications to date chose to isolate these individual components, we feel that many synergistic benefits accrue by taking a more holistic modern approach to a problem.

The well-known and extensively studied Wolff-Staudinger reactions to afford $\beta$-lactams via [2+2] cycloaddition of ketenes with imines is a case in point. While achievable under a variety of conditions with a wide substrate scope, stereoselectivity and scale-up can be problematic for this transformation. In particular, the high temperature and release of gaseous nitrogen as a by-product upon Wolff rearrangement of $\alpha$ diazacarbonyl compounds to produce intermediate ketenes is seen as a hazardous transformation ${ }^{1}$ despite the value of the final $\beta$-lactam cycloaddition products.
In the first phase of the program we examined the heating efficiency of a recently delevoped single-mode bench-top continuous-flow microwave apparatus ${ }^{2}$ for the improved generation of primary ketenes from $\alpha$-diazoketones by Wolff rearrangement at high temperature. We tested the reproducibility of the equipment to function over an extended period of time, monitoring some crucial parameters in real time. A good ratio between the irradiating power and the reflecting power was observed, showing a good efficiency of the system in maintaining constant field strength (figure 1a). ${ }^{3}$ Pressure regulators installed in front and back-end of the flow borosilicate glass reactor allowed an accurate control of the pressure inside the system (figure $1 \mathrm{~b}$ ). The monitoring of the temperature under classical sealed-vessel microwave conditions is often not easy, as classical direct temperature sensors such as thermometers or thermocouples can interfere with the electromagnetic field. ${ }^{4}$ In our flow microwave set-up, the temperature inside the reactor could be continuously monitored by a thermocouple installed at the exit of the coil, without affecting the uniformity of the electromagnetic field. Once the steady state was reached, an impressive stability of the temperature was recorded (figure 1c). The maximum temperature reached was dependent on the irradiating power and on the residence time of the solution inside the irradiating cavity. The steady state was reached faster at higher flow rate, thus at low residence time (figure 1d). This is in accordance with the reported studies on the efficiency of energy transfer of the microwave irradiation into heat, which can be affected by the additional reflection of the microwaves inside the irradiation cavity. ${ }^{3}$ In order to assess the reliability of the temperature measurement by the thermocouple a sequence of thermal images were captured over the time. For this purpose a thermal camera was directed at a slit positioned on one wall of the microwave cavity, containing the reactor tube. A uniform temperature distribution was reached after few minutes throughout the borosilicate glass reactor (for more details see ESI). 

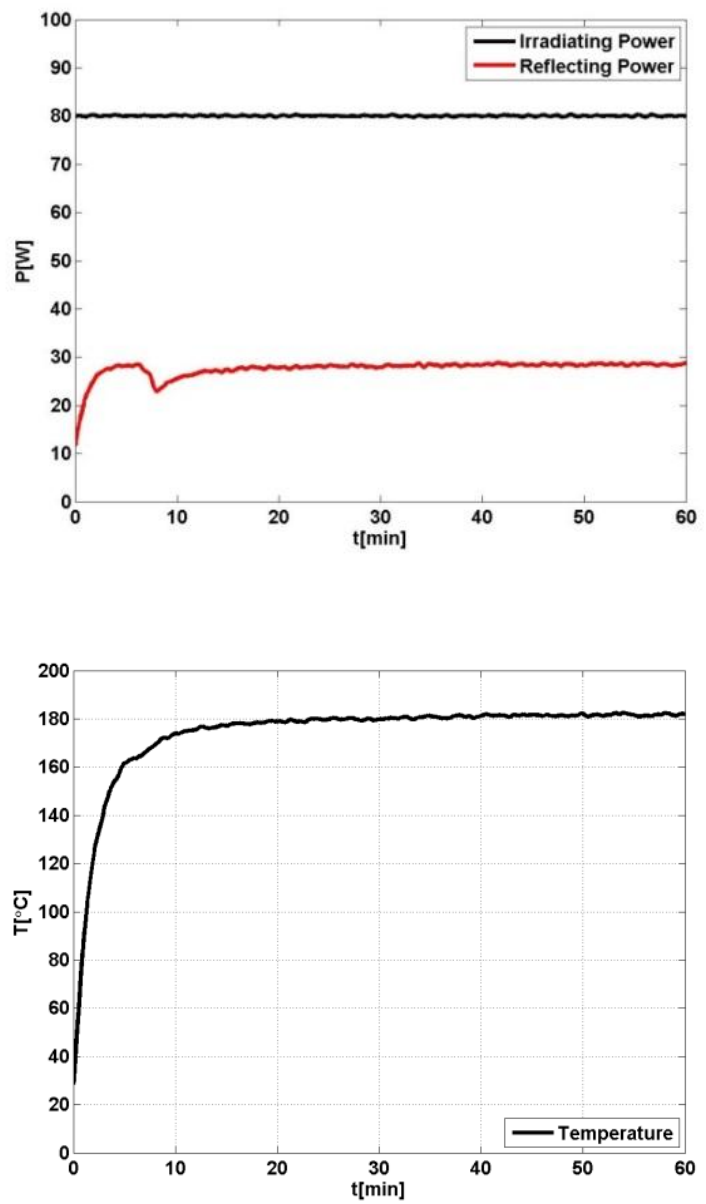

c)

d)

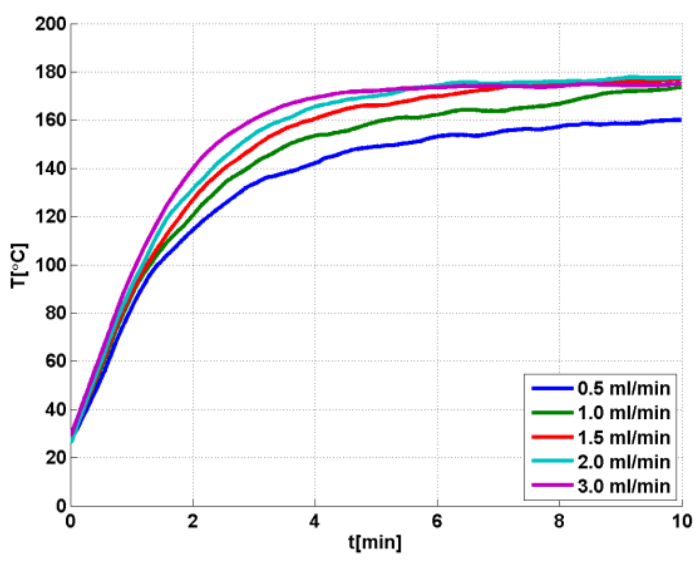

Figure 1 a) Irradiating power and reflecting power over $1 \mathrm{~h}$. Solvent: acetonitrile; flow rate: $1.0 \mathrm{ml} / \mathrm{min}$; back pressure regulator (BPR): 20 bar. b) Inlet pressure and outlet pressure over $1 \mathrm{~h}$. Solvent: acetonitrile; flow rate: $1.0 \mathrm{ml} / \mathrm{min}$; back pressure regulator (BPR): 20 bar. c) Temperature measured by a thermocouple at the exit of the reactor over $1 \mathrm{~h}$. Solvent: acetonitrile; flow rate: $1.0 \mathrm{ml} / \mathrm{min}$; back pressure regulator (BPR): 20 bar. d) Temperature measured by a thermocouple at the exit of the reactor at different flow rate $(0.5,1.0,1.5,2.0$ and $3.0 \mathrm{ml} / \mathrm{min})$. Solvent: acetonitrile; back pressure regulator (BPR): 20 bar.

As a proof of concept, a new equipment was applied to the generation of ketene from $\alpha$-diazoketone followed by the in situ trapping with benzylamine (scheme 1).

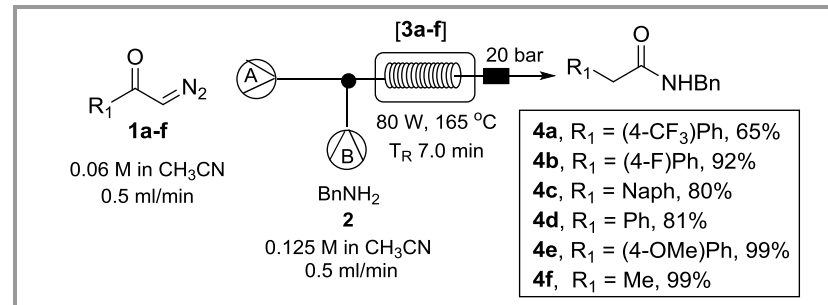

Scheme 1 Flow-continuous microwave-assisted Wolff rearrangement of $\alpha$ diazoketones $1 \mathrm{a}-\mathrm{f}$ and in situ ketene $3 \mathrm{a}-\mathrm{f}$ trapping with benzylamine $\mathbf{2}$.

The solvent, the reagents concentration, the irradiation power and the flow rate were accurately adjusted in order to reduce collateral reactions due to the extremely high reactivity of the heated ketenes. ${ }^{5}$ The best results were observed when the reaction mixture in acetonitrile was passed through the reactor at $1.0 \mathrm{ml} / \mathrm{min}$ and heated at $165^{\circ} \mathrm{C}$ by irradiating with a power of 80 Watt. Thus a solution $(0.06 \mathrm{M}$ in acetonitrile) of different $\alpha$-diazoketones 1a-f was pumped and then mixed with a solution of benzylamine $2(0.125 \mathrm{M}$ in acetonitrile) before passing through the helical tubular borosilicate glass reactor contained in the resonant cavity. The resulting amides 4a-f were isolated in good yields (65-99\%) after passing through the reactor at $1 \mathrm{ml} / \mathrm{min}$ (residence time $=7$ minutes) and heated at $165^{\circ} \mathrm{C}$ by $80 \mathrm{~W}$ irradiation.

The safety and the reliability of the system during the reaction scale-up were evaluated by attempting a continuous multigram synthesis of the amide 4 ff. The crucial parameters (temperature and pressure) were stable over the reaction time and the preparation of $\mathbf{4 f}$ was accomplished in $7 \mathrm{~h}$, with no need for further purification (15 mmoles, 2.4 grams).

Interestingly, similar results were not observed when the same reaction mixture was performed under standard sealed vessel microwave conditions. Attempts to generate the ketenes via more conventional conductive heating in flow were also performed. The reagent mixture was passed continuously through a stainless steel coil under different reaction conditions (solvent, temperature, flow rate). In all the cases a lower conversion and a poorer selectivity were observed, thereby further demonstrating the efficiency of the new microwave flow set-up.

Our group recently reported on the flow reaction of imines with mono-alkyl and phenyl ketenes, generated by zincmediated dehalogenation of $\alpha$-bromo acyl bromides at room temperature, to provide $\beta$-lactams. The final products were 
obtained in good yields but with variable diastereomeric ratios. ${ }^{6}$ In an attempt to demonstrate the beneficial effect of a fast microwave-assisted heating of the reagents, we decided to apply the above protocol of the Wolff generated ketenes in combination with a Staudinger cycloaddition reaction particularly with regard to the stereoselective outcome.

A number of differently substituted $\alpha$-diazoketones and imines were reacted under the above optimized reaction conditions for the synthesis of amides (solvent: $\mathrm{MeCN}$; flow rate 0.5 $\mathrm{ml} / \mathrm{min}$ per pump; irradiating power: $80 \mathrm{~W}$; temperature: 165 ${ }^{\circ} \mathrm{C}$.

When aliphatic, aryl and heteroaryl $\alpha$-diazoketones, 1e-i, were reacted with $N$-benzylidene benzylamine $(E)-\mathbf{5 a}$, a range of $\beta$ lactams 6a-e were obtained in good yields (up to 85\%) and with high comparable diastereoselectivity (scheme 2).

The specific substitution pattern of the imine was also evaluated, by reacting different imines $(E)-\mathbf{5 a}-\mathbf{m}$ with one specific $\alpha$-diazoketone 1e, affording $\beta$-lactams $\mathbf{6 a}$ and $\mathbf{6 g - r}$ (13 examples, scheme 2). A preferential formation of transconfigured $\beta$-lactams was observed in all these cases, with the exception of $\mathbf{6 j}$ (dr trans/cis 1:16.4), 6k (dr trans/cis 1.1:1) and 6r (dr trans/cis 1:1).

The size of the substituent at the nitrogen atom of the imine likely affected the stereochemical outcome of the [2+2] Staudinger cycloaddition. The preferential formation of transconfigured $\beta$-lactams was observed for $\mathbf{6 g}\left(\mathrm{R}_{2}=\mathrm{Me}\right)$ and $\mathbf{6 h}\left(\mathrm{R}_{2}\right.$ $=n$-Bu). When imine $(E)-\mathbf{5 d}\left(\mathrm{R}_{2}=i-\mathrm{Pr}, \mathrm{R}_{3}=\mathrm{Ph}\right)$ was reacted with ketene 1e, $\beta$-lactam $\mathbf{6 i}$ was formed as a mixture of transand cis-configured products (dr trans/cis 3.2:1). Interestingly, when the imine $(E)-\mathbf{5 e}\left(\mathrm{R}_{2}=t-\mathrm{Bu}, \mathrm{R}_{3}=\mathrm{Ph}\right)$, containing a bigger substituent at the nitrogen atom, was reacted with $\mathbf{1 e}$, the formation of the $\beta$-lactam $\mathbf{6 j}$ proceeded stereoselectively in favour of the cis-configured product (dr trans/cis 1:16.4). Similar effect of the size of the substituent at the nitrogen of the imine was observed during the formation of $N$-benzyl $\beta$ lactams (6a and 6r). The [2+2] Staudinger cycloaddition reaction proceeded stereoselectively (dr trans/cis 24:1) and in high yields $(85 \%)$ for $\mathbf{1 e}\left(\mathrm{R}_{1}=4-(\mathrm{MeO}) \mathrm{Ph}\right)$ with $(E)-\mathbf{5 a}\left(\mathrm{R}_{2}=\right.$ $\mathrm{Bn}, \mathrm{R}_{3}=\mathrm{Ph}$ ), giving $\mathbf{6 a}$. In contrast, $\beta$-lactam $6 \mathbf{r}$ was obtained in poor yield (30\%) and with no diastereoselectivity ( $\mathrm{dr}$ trans/cis $1: 1)$ by reaction of $\mathbf{1 e}\left(\mathrm{R}_{1}=4-(\mathrm{MeO}) \mathrm{Ph}\right)$ with $(E)-\mathbf{5 a}\left(\mathrm{R}_{2}=\right.$ $\mathrm{CHPh}_{2}, \mathrm{R}_{3}=\mathrm{Ph}$ ).

Also the effect of the substitution at the $\mathrm{sp}^{2}$ carbon of the imine was considered, reacting diazoketone 1e with different $\mathrm{N}$ benzylideneimines, $(E)-\mathbf{5 g}-\mathbf{j}$ under our conditions. When the electron-rich imine $(E)-5 \mathbf{i}\left(\mathrm{R}_{2}=\mathrm{Ph}, \mathrm{R}_{3}=(4-\mathrm{MeO}) \mathrm{Ph}\right)$ was reacted with 1e, $\beta$-lactam $6 \mathrm{~m}$ was obtained in good yield (61\%) and high diastereomeric ratio ( $\mathrm{dr}$ trans/cis 9:1). However, when the electron-poor imines $(E)-\mathbf{5 g}\left(\mathrm{R}_{2}=\mathrm{Ph}, \mathrm{R}_{3}=\right.$ Pyridin-2-yl $)$ and $(E)-5 \mathbf{j}\left(\mathrm{R}_{2}=\mathrm{Ph}, \mathrm{R}_{3}=\left(4-\mathrm{CF}_{3}\right) \mathrm{Ph}\right)$ were employed under the same reaction conditions, the resulting $\beta$ lactams $\mathbf{6 1}$ and $\mathbf{6 0}$ were formed in lower yields (respectively $56 \%$ and $47 \%$ ) and lower diastereomeric ratio (respectively $\mathrm{dr}$ trans/cis 3.8:1 for $\mathbf{6 l}$ and 5:1 for $\mathbf{6 o}$ ). In order to demonstrate the additive effect of the substitution at the nitrogen atom and the substituent at the $\mathrm{sp}^{2}$ carbon of the imine, ketene 1e was reacted with imine $(E)-\mathbf{5 f}\left(\mathrm{R}_{2}=i\right.$ - $\mathrm{Pr}, \mathrm{R}_{3}=$ Pyridin-2-yl). The resulting $\beta$-lactam $6 \mathbf{k}$ was obtained with no diastereoselectivity (dr trans/cis 1.1:1), confirming the crucial role of the substitution pattern of the imine in controlling the stereochemical outcome of this transformation.

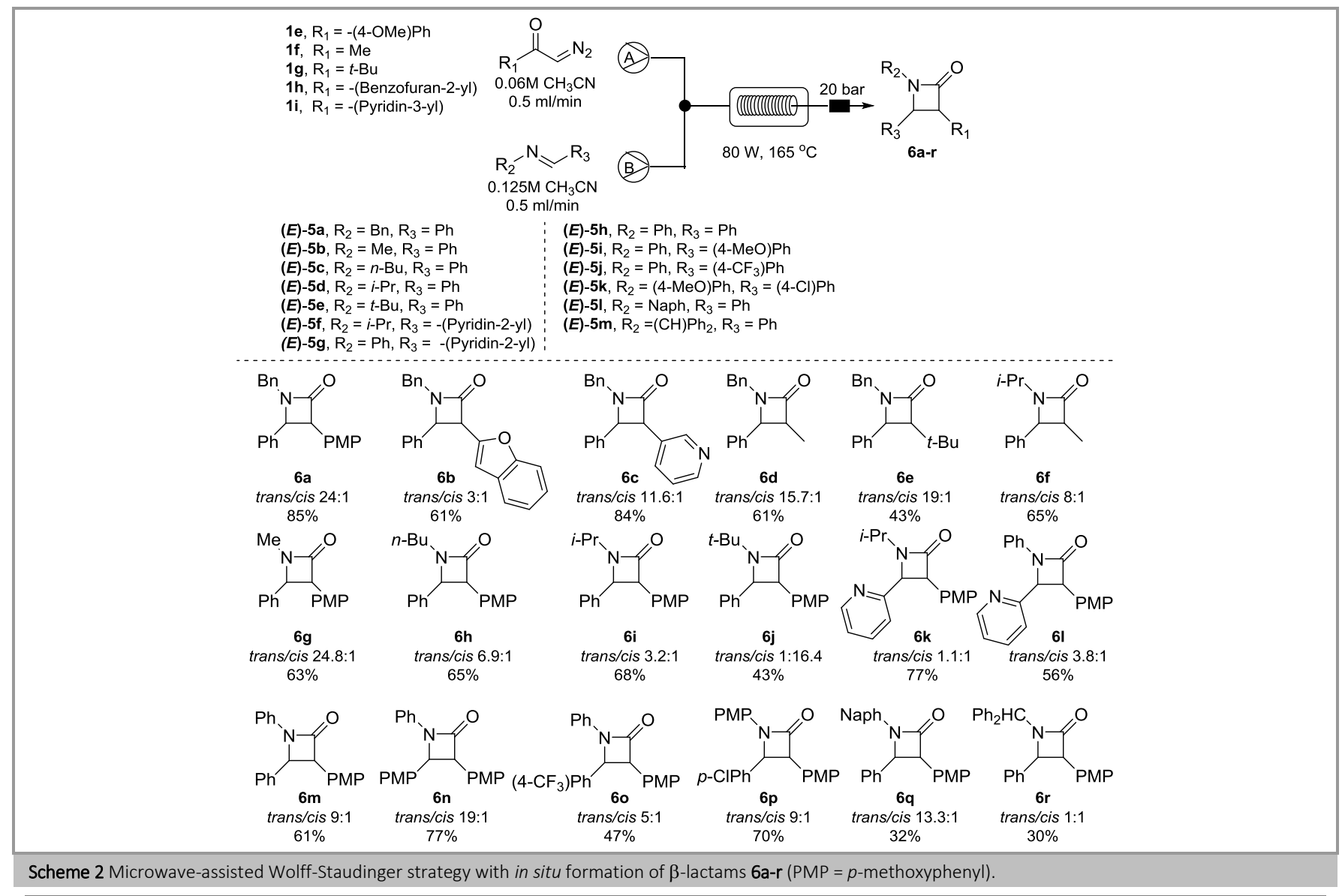


These experimental results demonstrated that high diastereoselectivity in the Staudinger reaction can be achieved under high-temperature conditions for a wide range of $\alpha$ diazoketones with appropriate imines. Also, the high temperature reached in the flow-microwave reactor, as recorded in our experiments, appears to be a crucial parameter for the stereoselectivity of the reaction. ${ }^{7}$

In order to suggest a mechanistic model and ultimately to rationalize and predict the stereochemical outcome of the $[2+2]$ ketene-imine cycloaddition reaction at high temperature, computational studies at the Density Functional Theory (DFT) level were performed. A number of experimental mechanistic studies $^{8}$ of the [2+2] ketene-imine cycloaddition together with DFT level calculations ${ }^{9}$ were previously reported in the literature. Nevertheless, to the best of our knowledge, none of the quantum chemistry calculations have been used to describe the system at high temperature. Therefore, we decided to perform a computational analysis taking into account the experimental conditions.

According to the reported mechanism of this transformation, ${ }^{8}$ the initial nucleophilic addition of imine $\mathbf{5}$ to ketene $\mathbf{3}$ would lead to the formation of a zwitteronic intermediate, $\mathbf{Z W}$, which in the subsequent cycloaddition step would provide the final $\beta$ lactam 6 (scheme 3).

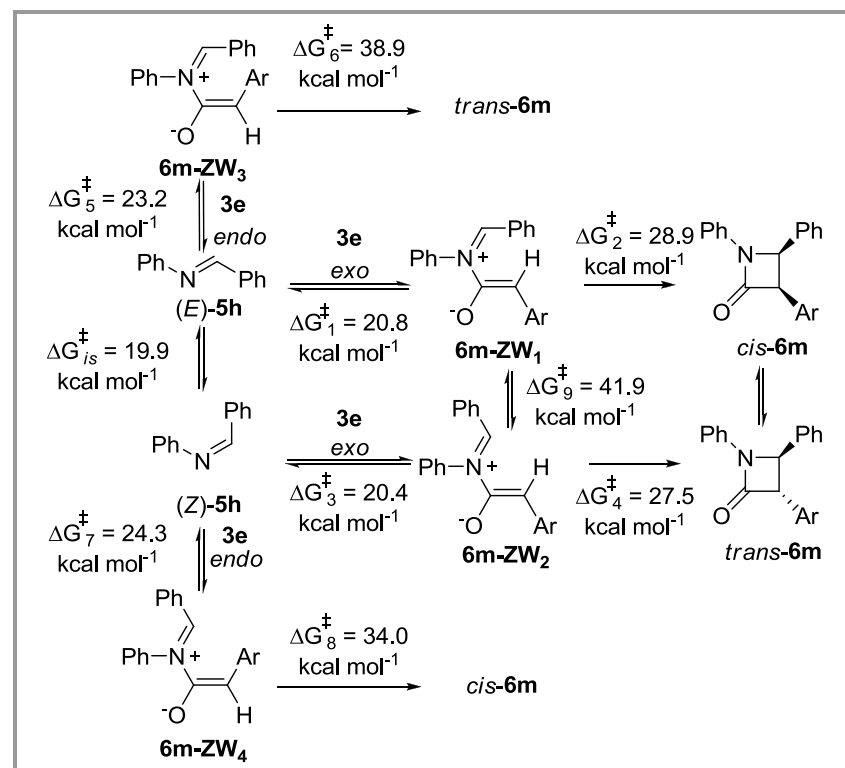

Scheme 3 Possible reaction pathways for the formation of cis- and translactams $6 \mathrm{~m}$ by $[2+2]$ imine-ketene cycloaddition reaction $(\mathrm{Ar}=(4-\mathrm{MeO}) \mathrm{Ph})$; the Gibbs energies shown are Gibbs energies of activation where $(E)-5 \mathrm{~h}+3 \mathrm{e}$ is set as the ground state; barriers $\Delta \mathrm{G}^{7}{ }_{1}, \Delta \mathrm{G}^{7}{ }_{2}, \Delta \mathrm{G}^{7}{ }_{3}, \Delta \mathrm{G}^{7}{ }_{4}, \Delta \mathrm{G}^{7}$ is, $\Delta \mathrm{G}^{7}{ }_{5}, \Delta \mathrm{G}^{\neq}{ }_{6}$, $\Delta \mathrm{G}^{\neq}, \Delta \mathrm{G}^{\neq}, \Delta \mathrm{G}^{\neq}{ }_{9}$ correspond to the transition states $6 \mathrm{~m}-\mathrm{TS}_{1}, 6 \mathrm{~m}-\mathrm{TS}_{2}, 6 \mathrm{~m}-\mathrm{TS}_{3}$, $6 \mathrm{~m}$ - $\mathrm{TS}_{4}, 5 \mathrm{~h}-\mathrm{TS}, 6 \mathrm{~m}-\mathrm{TS}_{1}$-endo, $6 \mathrm{~m}$ - $\mathrm{TS}_{2}$-endo, $6 \mathrm{~m}$ - $\mathrm{TS}_{3}$-endo, $6 \mathrm{~m}-\mathrm{TS}_{4}$-endo, $6 \mathrm{~m}$ ZW-is; see ESI for 3D structures).

Firstly, the computational analysis aimed to evaluate Gibbs activation energies of the nucleophilic addition of the two isomeric imines, $(E)-\mathbf{5 h}$ and $(Z)-\mathbf{5 h}\left(\mathrm{R}_{2}=\mathrm{R}_{3}=\mathrm{Ph}\right)$, to the ketene 3e $\left(\mathrm{R}_{1}=(4-\mathrm{MeO}) \mathrm{Ph}\right)$ in endo- and exo-fashion at high temperature $\left(165^{\circ} \mathrm{C}\right)$. Irrespective of the imine configuration, the $e x o$-addition was found to have a slightly lower energy barrier than the endo-counterpart $\left(\Delta \mathrm{G}_{1} \#=20.8\right.$ and $\Delta \mathrm{G}_{3}{ }^{\#}=20.4$ $\mathrm{kcal} \mathrm{mol}{ }^{-1}$ vs $\Delta \mathrm{G}_{5}{ }^{\#}=23.2$ and $\Delta \mathrm{G}_{7}^{\#}=24.3 \mathrm{~mol}^{-1}$; scheme 3). The subsequent conrotatory ring-closure step was characterized with significantly higher energy barriers for the endo-addition paths than for the exo-counterparts $\left(\Delta \mathrm{G}_{6} \#=38.9 \mathrm{kcal} \mathrm{mol}^{-1}\right.$ for $\mathbf{6 m}-\mathbf{Z W}_{3}$ and $\Delta \mathrm{G}_{8}^{\#}=34.0 \mathrm{kcal} \mathrm{mol}^{-1}$ for $\mathbf{6 m}-\mathbf{Z W}_{4}$ vs $\Delta \mathrm{G}_{2}{ }^{\#}=28.9$

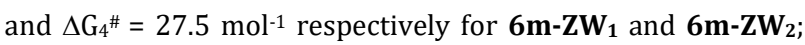
scheme 3). Based on these results, the endo-addition pathways were discarded from further studies for other imines. Among other possible pathways that may explain the formation of stereoisomeric lactams $\mathbf{6 m}$, the $E / Z$ isomerization of the zwitterionic intermediates $\mathbf{6} \mathbf{m}-\mathbf{Z W}_{\mathbf{1}}$, and $\mathbf{6} \mathbf{m}-\mathbf{Z} \mathbf{W}_{\mathbf{2}}$ was considered. This possibility was also disregarded because it would involve a rotation around the $\mathrm{C}=\mathrm{N}$ bond, which would require a high energy barrier $\left(\Delta \mathrm{G}_{9}^{\#}=41.9 \mathrm{kcal} \mathrm{mol}^{-1}\right.$; scheme $3)$. The $\mathrm{C}=\mathrm{N}$ double bonds in the range of imines and zwitterionic intermediates were characterized with similar bond lengths (differences are within 1.5\%; see table 1 in supporting information). This evidence suggested that they all have similar double bond character and therefore similar rotation barriers. ${ }^{10}$

Gibbs energies of different $(E)$ - and $(Z)$-imines $(\mathbf{5 b}, \mathbf{5 d}, \mathbf{5 e}, \mathbf{5 h}$, 51 and $\mathbf{5 m}$ with $\mathrm{R}_{3}=\mathrm{Ph}, \mathrm{R}_{2}=\mathrm{Me}, i-\mathrm{Pr}, t-\mathrm{Bu}, \mathrm{Ph}, \mathrm{Naph},(\mathrm{CH}) \mathrm{Ph}_{2}$, respectively; $\mathbf{5 f}$ and $\mathbf{5 g}$ with $\mathrm{R}_{3}=$ Pyridin-2-yl, $\mathrm{R}_{2}=i-\mathrm{Pr}, \mathrm{Ph}$ respectively), were calculated at $165^{\circ} \mathrm{C}$, finding the $(E)$-imines to be significantly more stable than their $(Z)$-counterparts for all six cases. Two alternative pathways were initially considered for the $E / Z$ imine isomerization: 1) via nucleophilic attack to the carbon of the iminium double bond, followed by rotation and elimination; 2) via nitrogen inversion in the starting imine. As the reaction was performed in acid and metal-free conditions using dry aprotic solvent (acetonitrile), the first hypothesis was not comprehensively evaluated. The second hypothetic pathway was studied deeper and the transition state 5-TS with the linear configuration of the $\mathrm{C}=\mathrm{N}-\mathrm{R}$ moiety was characterized for the most representative cases. ${ }^{11}$ As expected, due to stabilization of the linear configuration by the aromatic system, ${ }^{12}$ the isomerization of the imines $\mathbf{5 h}, \mathbf{5 g}$ and $\mathbf{5 l}$ were characterized with lower energy barriers $\left(\Delta \mathrm{G}_{i s^{*}}\right.$ 19.9, 23.2 and $18.5 \mathrm{kcal} \mathrm{mol}^{-1}$; figure 4) than other $N$-alkyl imines $\left(\Delta \mathrm{G}_{\text {is }^{*}}\right.$ 28.2, 28.6, 25.8, 27.9, 27.0 for $\mathbf{5 b}, \mathbf{5 d}, \mathbf{5 e}, \mathbf{5 f}$ and $\mathbf{5 m}$ respectively; for more details see ESI).

The possibility of the trans-cis isomerization of the $\beta$-lactams via either retro-Staudinger cycloaddition ${ }^{13}$ or enolization reactions was also considered. In order to verify whether this side reaction occurs experimentally, a mixture of $6 \mathbf{r}$ in acetonitrile (dr trans/cis 50/50) was treated under our reaction conditions (power $80 \mathrm{~W}$, temperature $165^{\circ} \mathrm{C}$ ). The reaction mixture then was analyzed by ${ }^{1} \mathrm{H}$ NMR spectroscopy, revealing that the diastereomeric ratio of the product mixture was unchanged with regard to the starting $\beta$-lactams mixture. The facts that the ratio of the two products cis- and trans-6r remained the same could be explained either by assuming an established thermodynamic equilibrium between the two species, or absence of the products interconverting. If the system was at the thermodynamic equilibrium, according to the DFT calculations, trans-configured product would be the prevailing component in the reaction mixture (trans/cis ratio of 3:1, calculated from $\Delta \mathrm{G}_{\mathrm{f}}$ (trans) $=-15.8$ and $\Delta \mathrm{G}_{\mathrm{f}}$ (cis) $=-14.6$ $\mathrm{kcal}^{\mathrm{mol}}{ }^{-1}$ respectively). This theoretical finding, contradicting with the experimental result (trans/cis ratio of 1:1), could be used to rule out the trans/cis isomerization of the lactams $6 r$ as 
a factor affecting the stereochemical outcome of the [2+2] Staudinger cycloaddition reaction.

The elementary reaction steps of the [2+2] Staudinger cycloaddition ${ }^{14}$ was performed to elucidate the operational mechanism (scheme 4).

$$
\text { -3 }
$$

Scheme 4 Suggested operational mechanism for the formation of cis- and trans-lactams 6 by [2+2] imine-ketene cycloaddition reaction.

The steady state approximation ${ }^{15}$ could be applied to describe the transformations of the zwitterionic intermediates $\mathbf{6 - Z W _ { 1 }}$ and $\mathbf{6}-\mathbf{Z W}_{2}$. The activation Gibbs energies of the key elementary steps were computed for a number of cases exhibiting different stereochemical outcome (table 1): nucleophilic exo-addition of $E / Z$ imines 5 to the ketene $\mathbf{3 e}$ $\left(\Delta \mathrm{G}^{\neq_{1}}\right.$ and $\Delta \mathrm{G}^{\neq_{3}}$ for $(E)$ - and $(Z)$-imines); conrotatory ring closure of zwitterionic intermediates $\left(\Delta \mathrm{G}^{{ }_{2}}\right.$ and $\Delta \mathrm{G}^{{ }_{4}}$ for $\mathbf{6}-\mathbf{Z W}_{\mathbf{1}}$ and 6-ZW $\left.\mathbf{Z W}_{2}\right) ; E / Z$ imine 5 isomerization $\left(\Delta \mathrm{G}^{*_{i s}}\right.$; table 1$)$. These values were used to choose the mechanistic model applicable for the prediction of the diastereomeric ratios of the final products 6 .

It was found that in all computed cases the conrotatory ring closure of both zwitterionic intermediates $\mathbf{6}-\mathbf{Z W}_{\mathbf{1}}$ and $\mathbf{6}-\mathbf{Z W}_{\mathbf{2}}$ was characterized with significantly higher barrier than the nucleophilic addition of the corresponding imine $\mathbf{5}$ to the ketene 3 (compare both $\Delta \mathrm{G}^{\neq} 2$ and $\Delta \mathrm{G}^{\neq_{4}}$ against $\Delta \mathrm{G}^{\neq_{1}}$ and $\Delta \mathrm{G}^{{ }_{3}}$, accordingly; table 1). Moreover, the computed barrier for the ring closure of the intermediate $\mathbf{6 - Z W 1}$ derived from the imine
(E)-5 ( $\Delta \mathrm{G}^{ \pm} 2$; table 1) was found to be either higher (entries 1, 4, 6 - 9; table 1) or similar (entries 2, 3, 5; table 1) to the imine (E)-5 isomerisation barrier $\left(\Delta \mathrm{G}^{{ }_{\mathrm{i}}}\right.$; table 1$)$. Taking into account the low concentration of the ketene intermediate $\mathbf{3}$ in the reaction media, the first-order trans-cis isomerisation of the imines $\mathbf{5}$ is expected to be much faster than the second-order [2+2] Staudinger reaction between isomeric imines $\mathbf{5}$ and a ketene 3. The Curtin-Hammett principle ${ }^{15}$ could be applied and the expected trans/cis ratios of $\beta$-lactams 6 could be calculated from $\Delta \Delta \mathrm{G}^{\#}$ of conrotatory ring closure steps.

In order to confirm that the Curtin-Hammett principle can be successfully applied to predict trans/cis ratios for all studied cases, the diastereomeric ratios of the products $\mathbf{6}$ for the cases where imine isomerization and the lactam ring closure had similar reaction barriers (compare $\Delta \mathrm{G}_{2}{ }^{\#}$ and $\Delta \mathrm{G}_{\text {is }}{ }^{\#}$ for entries 2 , 3,5 ; table 1 ) were re-calculated using the differential rate law ${ }^{16}$ and the activation Gibbs energy of the ketene 3e formation from the diazocompound 1e equal to $32.2 \mathrm{kcal} \mathrm{mol}^{-1}$ at $165{ }^{\circ} \mathrm{C}$ (see ESI for details). It was found that both approaches give the same values for trans/cis ratios providing a good agreement with the experimental results.

It can be concluded from the computational studies that the conrotatory ring closure step was the stereochemistry determining step. For a number of the computed cases, the ring closure of the zwitterion $\mathbf{Z W}_{2}$, deriving from the imine $(Z)-\mathbf{5}$ was characterized with a lower barrier $\left(\Delta \mathrm{G}_{4^{*}}\right.$, table 1$)$ than the counterpart $\mathbf{Z} \mathbf{W}_{\mathbf{1}}$, deriving from the imine $(E)-\mathbf{5}\left(\Delta \mathrm{G}_{2^{*}}\right.$, table 1$)$. This could explain the trans-stereoselectivity observed experimentally during the [2+2] Staudinger cycloaddition reaction. However, introducing sterically large substituents $\left(R_{2}\right)$ on the imine nitrogen, or electron-poor substituents $\left(R_{3}\right)$ into the imine structure, diminished the difference between the rates of conrotatory closure steps of the zwitterions $\mathbf{Z W}_{\mathbf{1}}$ and $\mathbf{Z W}_{2}$. This resulted in deteriorated (entries 3, 5, 6 and 9; table 1) or reversed (entry 4; table 1) stereoselectivity of the [2+2] Staudinger reaction.

Table 1 Predicted and experimental stereoselectivity of the $[2+2]$ Staudinger reaction $\left(T=165^{\circ} \mathrm{C}\right) .{ }^{a}$

\begin{tabular}{|c|c|c|c|c|c|c|c|c|c|c|c|c|}
\hline Entry & Comd & $\mathrm{R}_{1}$ & $\mathrm{R}_{2}$ & $\mathrm{R}_{3}$ & $\Delta G_{i s}^{\neq}$ & $\Delta \mathrm{G}_{1}^{\neq}$ & $\Delta \mathrm{G}_{2}{ }^{\neq}$ & $\Delta \mathrm{G}_{3}{ }^{\neq}$ & $\Delta \mathrm{G}_{4}^{\neq}$ & $\Delta \Delta G^{\neq b}$ & 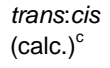 & $\begin{array}{l}\text { trans:cis } \\
(\exp .)^{d}\end{array}$ \\
\hline 1 & $6 f$ & $\mathrm{Me}$ & $i-\operatorname{Pr}$ & $\mathrm{Ph}$ & 28.6 & 21.1 & 31.8 & 26.4 & 30.0 & $-1.8(-1.8)$ & $8: 1$ & $8: 1$ \\
\hline 2 & $6 \mathrm{~g}$ & $p$-MeOPh & $\mathrm{Me}$ & $\mathrm{Ph}$ & 28.2 & 17.3 & 27.7 & 20.0 & 24.3 & $-3.4(-2.8)$ & $49: 1$ & $25: 1$ \\
\hline 3 & $6 i$ & $p$-MeOPh & $i-\operatorname{Pr}$ & $\mathrm{Ph}$ & 28.6 & 20.4 & 28.9 & 22.3 & 27.1 & $-1.8(-1.0)$ & $8: 1$ & $3: 1$ \\
\hline 4 & $6 j$ & $p$-MeOPh & $t$-Bu & $\mathrm{Ph}$ & 25.8 & 21.3 & 28.0 & 25.5 & 30.2 & $+2.2(+2.4)$ & $1: 12$ & $1: 16$ \\
\hline 5 & $6 k$ & $p$-MeOPh & $i-\operatorname{Pr}$ & $P y-2-\left.y\right|^{e}$ & 27.9 & 20.3 & 27.3 & 24.3 & 27.7 & $+0.4(0.0)$ & $1: 2$ & $1: 1$ \\
\hline 6 & 61 & $p$-MeOPh & $\mathrm{Ph}$ & Py-2-yl & 23.2 & 25.2 & 33.2 & 25.2 & 32.7 & $-0.5(-1.2)$ & $2: 1$ & $4: 1$ \\
\hline 7 & $6 m$ & $p$-MeOPh & $\mathrm{Ph}$ & $\mathrm{Ph}$ & 19.9 & 20.8 & 28.9 & 20.4 & 27.5 & $-1.4(-1.9)$ & $5: 1$ & $9: 1$ \\
\hline 8 & $6 q$ & $p$-MeOPh & Naph & $\mathrm{Ph}$ & 18.5 & 22.2 & 31.5 & 21.7 & 28.3 & $-3.2(-2.3)$ & $40: 1$ & $13: 1$ \\
\hline 9 & $6 r$ & $p$-MeOPh & $(\mathrm{CH}) \mathrm{Ph}_{2}$ & $\mathrm{Ph}$ & 27.0 & 21.1 & 29.4 & 24.6 & 29.9 & $+0.5(0.0)$ & $1: 2$ & $1: 1$ \\
\hline
\end{tabular}

[a] The Gibbs energies shown are Gibbs energies of activation (expressed in kcal mol ${ }^{-1}$ ), where $(E)-5+3$ is set as the ground state; barriers $\Delta \mathrm{G}^{\neq}{ }_{1}, \Delta \mathrm{G}^{\neq}{ }_{2}, \Delta \mathrm{G}^{\neq}{ }_{3}$, $\Delta \mathrm{G}_{4}^{\neq}, \Delta \mathrm{G}^{\neq}$is correspond to the transition states 6-TS $1,6-\mathrm{TS}_{2}, \mathbf{6}-\mathrm{TS}_{3}, \mathbf{6}$-TS 4 , 5-TS in all computed cases; see ESI for 3D structures. [b] Calculated by using the following formula: $\Delta \Delta \mathrm{G}^{\#}=\Delta \mathrm{G}_{4}^{\#}-\Delta \mathrm{G}_{2}^{\#}$. In brackets the values derived from experimental ratios. [c] Calculated at $\mathrm{T}=438 \mathrm{~K}\left(165{ }^{\circ} \mathrm{C}\right)$. [d] Determined by ${ }^{1} \mathrm{H}$ NMR of the reaction crude mixture. [e] Pyridin-2-yl is abbreviated as Py-2-yl. 

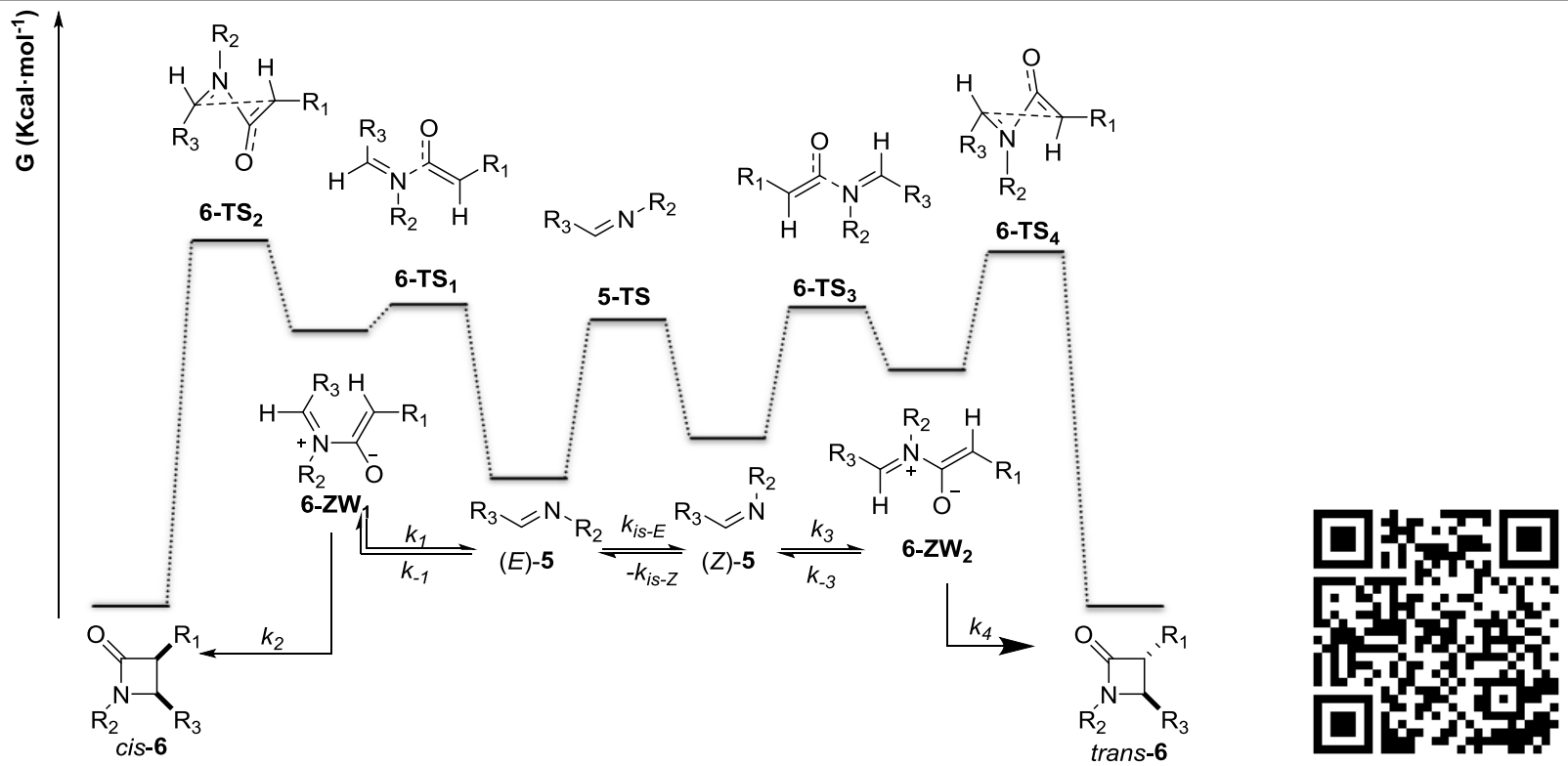

Figure 2 Reaction coordinates for the formation of cis- and trans-lactams 6 by [2+2] cycloaddition Staudinger reaction. Link to the animated 3D representation of the reaction pathways for the $[2+2]$ Staudinger cycloaddition reactions between $5 \mathrm{~h}$ and $3 \mathrm{e}$, at $165^{\circ} \mathrm{C}$ : https://es605.github.io/Staudinger/.

In the last phase of this investigation and in order to facilitate the interpretation of computational data, ${ }^{16}$ we studied the enhancement of the approach using a web-based Augmented Reality (AR) technology developed from open-source components (for technical details see ESI). Within the context of chemical applications several AR initiatives were previously reported, mainly for educational purposes. ${ }^{17}$ Nevertheless and to the best of our knowledge, there is no reported use of webbased AR in a chemical research program.

Our web-application allows the reader to quickly gain access to specific structural data with molecular visualization among the large number of computed structures reported in the current account. For each computed structure the reader is directed to an HTML document by scanning a QR code or via a URL link. ${ }^{18}$ The HTML document displays a 3D molecular representation of the structure, with the possibility for the reader to zoom, pan or rotate the 3D interactive structure, to hide the hydrogen atoms, to monitor structural parameters such as a single atom coordinates, interatomic distances, angles and dihedral angles, to export atoms coordinates as an XYZ file, or to access the 3D representation of other computed structures (figure 3a). Finally, if the device is equipped with a camera and upon allowance of the MediaStream request, ${ }^{19}$ the video stream is displayed on a canvas element and the reader is invited to scan a $2 \mathrm{D}$ fiducial marker associated to the structure. As soon as the Hamming-type marker ${ }^{20}$ is identified by the web application, it is overlaid with the 3D structure of the molecule (figure $3 \mathrm{~b}$; for details see ESI). The resulting Augmented Reality experience allows the reader to quickly load, visualize and interact with multiple molecular structures simultaneously within the web interface by scanning the multiple associated 2D markers (for a maximum of 1023 different markers). At last our web-based viewer was also successfully employed for the semi-automatic animation of reaction pathways by linear interpolation of each atom location between consecutive reaction points on the pathway. An application is the animated 3D representation of the reaction coordinates for the [2+2] Staudinger cycloaddition reactions between $\mathbf{5 h}$ and $\mathbf{3 e}$, at $165{ }^{\circ} \mathrm{C}$ (figure 2, for more details see ESI).
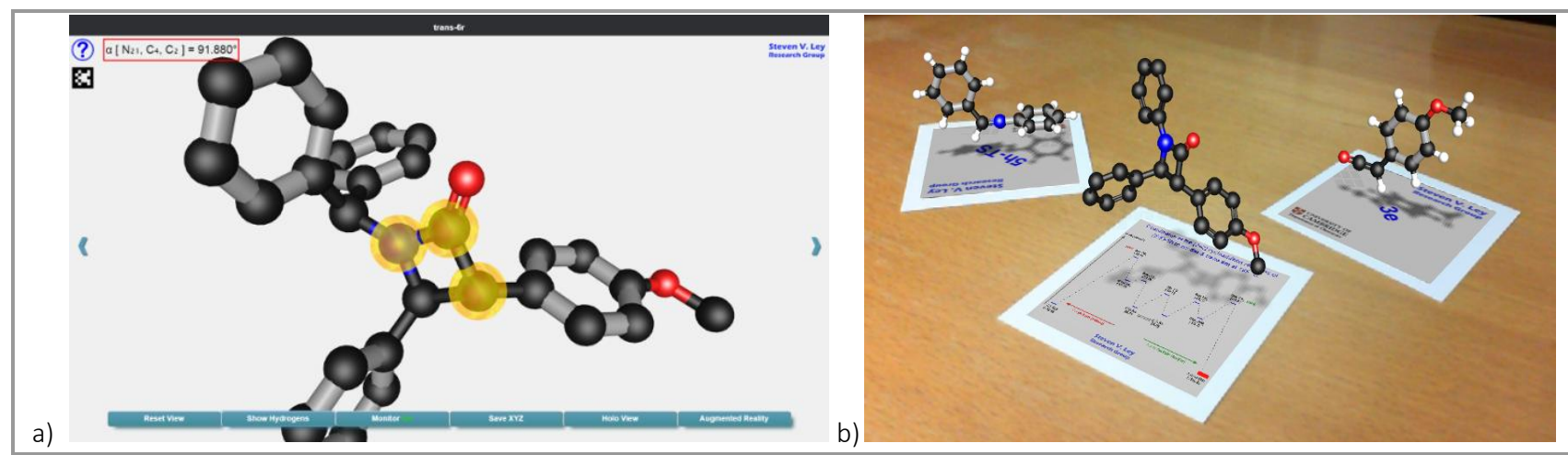

Figure 3 a) Screen capture of the web application showing available features. b) Screen capture of AR controls in operation. 
In conclusion, we described an efficient flow route for the generation and the reaction of hazardous and reactive intermediates in a fully contained environment. The high heating efficiency of a new flow microwave reactor was applied to the preparation of primary ketenes from a range of 2 diazoketones, which were in situ reacted with amines and imines affording respectively amides and $\beta$-lactams. The safety and the reliability of the system during the reaction scale-up were tested as demonstrated by the continuous multi-gram preparation of $N$-benzylproprionamide. Also the $\beta$-lactams were obtained in moderate to good yields and with a preferential trans-configuration. The operational mechanism of this transformation, involving fast isomerization step for both aliphatic and aromatic imines at high temperature, was rationalized by DFT level calculations. The resulting computed structures were represented by means of a new web-based Augmented Reality application, which should provide wider access and dissemination of molecular computational data.

The multi-disciplinary approach adopted in this work could find application in other similar synthesis programs.

\section{Instrumentation and general methods}

Flash column chromatography (FCC) was performed using Breckland Scientific silica gel 60, particle size 40-63 nm under air pressure. Analytical thin layer chromatography (TLC) was performed using silica gel 60 F254 pre-coated glass backed plates and visualized by ultraviolet radiation $(254 \mathrm{~nm})$ and/or potassium permanganate or ammonium molybdate as appropriate. Isolated yields are reported to 0 decimal places and "quant." signifies a yield of $99.5 \%$ or higher. $1 \mathrm{H}$ NMR spectra were recorded on Bruker DRX-400 (400 MHz) or DRX-600 (600 MHz) spectrometer. Chemical shifts are reported in ppm with the resonance resulting from incomplete deuteration of the solvent as the internal standard ( $\left.\mathrm{CDCl}_{3}: 7.26 \mathrm{ppm}\right)$. 13C NMR spectra were recorded on Bruker DRX-400 (100 MHz) or DRX-600 (150 MHz) spectrometer with complete proton decoupling. Chemical shifts are reported in ppm with the solvent resonance as the internal standard $\left(\mathrm{CDCl}_{3}: 77.0 \mathrm{ppm}\right)$. Data are reported as follows: chemical shift $\delta / \mathrm{ppm}$, multiplicity ( $\mathrm{s}=$ singlet, $\mathrm{d}=$ doublet, $\mathrm{t}=$ triplet, $\mathrm{q}=$ quartet, $\mathrm{br}=$ broad, $\mathrm{m}=$ multiplet or combinations thereof. $13 \mathrm{C}$ signals are singlets unless otherwise stated), coupling constants are reported in $\mathrm{Hz}$, integration $(1 \mathrm{H}$ only). $1 \mathrm{H}$ NMR signals are reported to 2 decimal places and 13C signals to 1 decimal place unless rounding would produce a value identical to another signal. In this case, an additional decimal place is reported for both signals concerned. 19F NMR signals are reported to 2 decimal places and trifluorotoluene was used as internal standard $(-63.72 \mathrm{ppm})$. High resolution mass spectrometry (HRMS) was performed on a Waters Micromass LCT spectrometer using electrospray ionization, time-of-flight analysis and Micromass MS software HRMS signals are reported to 4 decimal places and are within \pm $5 \mathrm{ppm}$ of theoretical values. Infrared spectra were recorded neat as thin films on a Perkin-Elmer Spectrum One FTIR spectrometer and only selected peaks are reported. Melting points were collected using a Stanford Research Systems Optimelt automated melting point system using a gradient of $1{ }^{\circ} \mathrm{C}$ per min. Unless stated otherwise, reagents were obtained from commercial sources and used without purification. The removal of solvent under reduced pressure was carried out on a standard rotary evaporator.

Geometries of all structures (minima and saddle points) were optimized at the $\omega \mathrm{B} 97 x d / c c-P V D Z$ level $\omega \mathrm{B} 97 x \mathrm{xD} / \mathrm{cc}-\mathrm{PVTZ} / / \omega \mathrm{B} 97 \mathrm{xD} / \mathrm{cc}-\mathrm{PVDZ}^{21}$ level calculations ${ }^{22}$ using the implicit Solvation Model based on Density (SMD) ${ }^{23}$ implemented in Gaussian 09 software $^{24}$ in acetonitrile as a solvent (using the SMD solvation model, $\varepsilon=35.688$ ). Subsequent vibrational frequency calculations were performed at the same level for all calculated structures. When needed, multiple initial guesses (no more than four) were used to explore the conformational space fully. All transition states thus found possess exactly one negative Hessian eigenvalue, while all other stationary points were confirmed to be genuine minima on the potential energy surface (PES). Intrinsic reaction coordinate (IRC) analysis was performed to unambiguously assign located transition states when needed. Electronic energies were obtained by performing single point calculations at the $\omega$ B97xd/cc-pVTZ level in solvent. Gibbs energies were calculated as $\Delta G=\Delta H-\mathrm{T} \Delta S$ at $438 \mathrm{~K}$ where enthalpies and entropies were obtained by using standard statistical mechanical formulae for the ideal gas, rigid rotor, and harmonic oscillator approximations following the normal-mode analysis in vacuum. A correction of $(3.0 \cdot \mathrm{D} n) \mathrm{kcal} \mathrm{mol}^{-1}$ (corresponding to the difference between the concentration of the ideal gas at $438 \mathrm{~K}$ and $1 \mathrm{~atm}$ and its $1 \mathrm{~mol} \mathrm{l}^{-1}$ concentration; $\mathrm{D} n$ is the change in number of moles in the reaction) has been applied in order that the computed values refer to $1 \mathrm{~mol} \mathrm{l}^{-1}$ standard state at a given temperature.

For each computed structure a JavaScript file was generated. This file consisted of an array of atoms describing the element and Cartesian coordinates for each atom and an array of bonds with their computed multiplicity. The JavaScript file was passed to a client-side HTML viewer where each atom object was constructed from a JavaScript atom object prototype, defining atomic radius ${ }^{25}$ and CPK colouring ${ }^{26}$ for each element. Each atom object was then rendered as an icosahedral geometric primitive at its location with the required radius and colour, using the WebGL API through the open-source three.js library. ${ }^{27}$ For each interatomic bond, two half-bond objects were generated. The two halfbond objects were parented with the atom object they respectively originate from before being rendered as two collinear cylindrical geometric primitives. For each half-bond geometry the direction was set parallel to the interatomic bond orientation, while the length was constrained to the half value of the interatomic distance. Both length and direction of the half-bond could be constrained for each frame, allowing the animation of the molecular structure by the only interpolation of the atoms position. The amount as well as the radius of cylindrical geometries for a single interatomic bond was defined by the computed multiplicity of the bond. For multiple bonds, cylindrical geometries were distributed on the plane defined by the positions of three geminal atoms. Considering the relatively low molecular weight of most of the computed structures, the 3D molecular representation of each molecule could be quickly achieved with a minimal amount of geometric primitives and without the need for the implementation of geometry shaders (i.e. raycasted geometry impostors) in WebGL1.0 in order to save on graphic rendering resources. ${ }^{28}$ However, as the simultaneous representation of several computed structures within the same WebGL renderer was required, each molecular structure was exported as a JSON file ${ }^{29}$ in order to be called on request. The molecular structures were rendered in a standard three.js scene. ${ }^{30}$ For the Augmented Reality, the camera calibration, adaptive thresholding, contours detection, corners sorting, markers identification and coplanar pose estimation were handled by the OpenCV.js and js-ArUco.js libraries. ${ }^{31}$ The resulting computed extrinsic parameters of the camera were then employed to overlay the molecular structures to their associated marker, with the help of a modified version of the skarf.js library, ${ }^{32}$ developed by our group. A simple performance test was carried out by tracking several ArUco markers simultaneously on a 640 x 480 pixel canvas HTML element, on a standard desktop PC (Dell ${ }^{\mathrm{TM}}$ Optiplex9010, 3.4 GHz Intel $囚$ Core $^{\mathrm{TM}}$ i 7-3770 CPU, 8 GB of RAM, Windows $7^{\text {TM }}-64$ bits) equipped with a web camera (Microsoft ${ }^{\circledR}$ LifeCam Cinema ${ }^{\mathrm{TM}}$, wide angle $\mathrm{F} / 2.0$ HD lens, 720p HD 30 fps, Autofocus) and running Mozilla Firefox ${ }^{\mathrm{TM}} 44.0$ or Google Chrome ${ }^{\mathrm{TM}} 48$.

\section{Procedures}

\section{General procedure for the preparation of 2-diazoketones 1a-i}

The compounds 1a-e and $\mathbf{1 h}-\mathbf{i}$ were prepared according to a reported procedure by reaction of bromoacetates with $N, N^{\prime}$-ditosylhydrazine and DBU. ${ }^{33}$ The compounds $\mathbf{1 f}$ and $\mathbf{1 g}$ were prepared according to a two-step reported procedure by reaction of acetylketones with 4acetamidobenzenesulfonylazide $\left(p\right.$-ABSA), ${ }^{34}$ and subsequent basic treatment $(\mathrm{NaOH} 1 \mathrm{M})$ of the resulting diazo-diketone derivatives. ${ }^{35}$ bromoacetates with $N, N^{\prime}$-ditosylhydrazine and DBU. ${ }^{33}$ The spectroscopic data of $1 \mathbf{f}^{34}$ and $\mathbf{1} \mathbf{g}^{36}$ are in accordance with the literature.

2-Diazo-1-[4-(trifluoromethyl)phenyl]-ethan-1-one. $1 \mathrm{1a}, \quad 52 \% .{ }^{1} \mathrm{H}$ NMR $\left(400 \mathrm{MHz}, \mathrm{CDCl}_{3}\right) \delta 7.86(\mathrm{~d}, J=8.1 \mathrm{~Hz}, 2 \mathrm{H}), 7.71(\mathrm{~d}, J=8.2 \mathrm{~Hz}, 2 \mathrm{H})$, 5.94 (s, $1 \mathrm{H}) .{ }^{13} \mathrm{C}$ NMR $\left(150.0 \mathrm{MHz}, \mathrm{CDCl}_{3}\right) \delta 184.9,139.4,134.1(\mathrm{q}, J=$ 
$32.7 \mathrm{~Hz}), 127.1,125.7(\mathrm{q}, J=3.7 \mathrm{~Hz}), 123.5(\mathrm{q}, J=272.3 \mathrm{~Hz}), 55.0 .{ }^{19} \mathrm{~F}$ NMR (100.0 MHz, $\left.\mathrm{CDCl}_{3}\right)$ 8 64.0. IR (Neat, $\mathrm{cm}^{-1}$ ) 3084, 2106, 1600, 1415 $1319,1111,860$. Elemental analysis calculated for $\mathrm{C}_{9} \mathrm{H}_{5} \mathrm{~F}_{3} \mathrm{~N}_{2} \mathrm{O}$ requires $\mathrm{C}$ $50.48 \%$, H 2.35\%, N 13.08\%; found C 50.88\%, H 2.30\%, N $12.60 \%$.

\section{General procedure for the preparation of amides 4a-f}

A solution of 2-diazoketone 1e-f $(0.06 \mathrm{M}$ in $\mathrm{MeCN})$ and benzylamine 2 $(0.12 \mathrm{M}$ in $\mathrm{MeCN})$ were pumped into the tubular glass reactor covered with a polytetrafluoroethylene film (i.d. $3.6 \mathrm{~mm}$, internal volume: 5.5-6.0 $\mathrm{mL}$ ) at the same flow rate (total flow rate of $1.0 \mathrm{~mL} \mathrm{~min}^{-1}$ ). An internal pressure of 2.0 MPa by a back pressure regulator (BPR) and a MW irradiation of $80 \mathrm{~W}$ were assured. After $10 \mathrm{~min}$ the exit temperature reached a steady state at $165^{\circ} \mathrm{C}$ (figure 3; red line), and the collection of the crude reaction mixture was started at this time. The crude product was concentrated in vacuo, and the residue was purified by flash column chromatography on silica gel (hexane/EtOAc) to give amides 4a-f. CAUTION: special precautions must be taken because the hazard associated with the diazocompounds and the ketene derivatives. All work was carried in a well ventilated fumehood, with an automatic shut down of the system in case of an increase of the temperature and pressure over the maximum value set. The spectroscopic data of $\mathbf{4} \mathbf{b},{ }^{37}$ $\mathbf{4 c},{ }^{38} \mathbf{4 d},{ }^{39} 4 \mathbf{e}^{40} \mathbf{4} \mathbf{f}^{36}$ are in accordance with the literature.

$\boldsymbol{N}$-benzyl-2-(4-(trifluoromethyl)phenyl)acetamide 4a, 65\%. ${ }^{1} \mathrm{H}$ NMR $\left(600 \mathrm{MHz}, \mathrm{CDCl}_{3}\right) \delta 7.61(\mathrm{~d}, J=8.05 \mathrm{~Hz}, 2 \mathrm{H}), 7.41(\mathrm{~d}, J=8.00 \mathrm{~Hz}, 2 \mathrm{H}), 7.32$ (d, $J=7.53 \mathrm{~Hz}, 2 \mathrm{H}), 7.28-7.34(\mathrm{~m}$ overlapping $\mathrm{d}$ at $7.32 \mathrm{ppm}, 1 \mathrm{H}), 7.22$ (d, $J=7.13 \mathrm{~Hz}, 2 \mathrm{H}), 5.89(\mathrm{br} \mathrm{s}, 1 \mathrm{H}), 4.43(\mathrm{~d}, J=5.8 \mathrm{~Hz}, 2 \mathrm{H}), 3.64(\mathrm{~s}, 2 \mathrm{H})$ ${ }^{13} \mathrm{C}$ NMR $\left(150.0 \mathrm{MHz}, \mathrm{CDCl}_{3}\right) \delta 169.7,138.8$ (br s), 137.8, 129.6, 129.59 $\left(\mathrm{q}, J_{\mathrm{C}-\mathrm{F}}=32.5 \mathrm{~Hz}\right), 128.7,127.62,127.59,125.8\left(\mathrm{q}, J_{\mathrm{C}-\mathrm{F}}=3.8 \mathrm{~Hz}\right), 124.0(\mathrm{q}$ $J_{C-F}=272.0 \mathrm{~Hz}$ ) , 43.8, 43.3. IR (neat, $\mathrm{cm}^{-1}$ ) 3238, 3063, 1625, 1556, 1328 , $1122,1070,753,698$. HRMS $m / z$ calculated for $\mathrm{C}_{15} \mathrm{H}_{15} \mathrm{~F}_{3} \mathrm{NO}[\mathrm{M}+\mathrm{H}]^{+}$ 294.1100 found 294.1090.

\section{General procedure for the preparation of imines $(E)-5 \mathrm{a}-\mathrm{m}$.}

The imines $(E)-\mathbf{5 a}$ and $(E)$-5b were obtained from commercial sources and used without purification. All the other imines were prepared according a reported procedure by reaction of appropriate aldehyde and imine in dichloromethane in presence of $\mathrm{MgSO}_{4}{ }^{41}$ The spectroscopic data of $(E)-\mathbf{5 c}-\mathbf{e},^{42}(E)-\mathbf{5 h}-\mathbf{j},{ }^{43}(E)-\mathbf{5 f},{ }^{44}(E)-\mathbf{5 g},{ }^{45}(E)-\mathbf{5} \mathbf{k},{ }^{46}(E)-\mathbf{5 l},{ }^{47}$ and $(E)-5 \mathbf{m}^{33}$ are in accordance with the literature.

\section{General procedure for the preparation of $\beta$-lactams 6a-s}

A solution of 2-diazoketone 1e-i $(0.06 \mathrm{M}$ in $\mathrm{MeCN})$ and the appropriate imine $5 \mathbf{a}-\mathbf{m}(0.12 \mathrm{M}$ in $\mathrm{MeCN})$ were pumped into the tubular glass reactor covered with a polytetrafluoroethylene film (i.d. $3.6 \mathrm{~mm}$, internal volume: $5.5-6.0 \mathrm{~mL}$ ) at the same flow rate (total flow rate of $1.0 \mathrm{~mL} \mathrm{~min}$ ${ }^{1}$ ). An internal pressure of $2.0 \mathrm{MPa}$ by a back pressure regulator (BPR) and a MW irradiation of $80 \mathrm{~W}$ were assured. After 10 min the exit temperature reached a steady state at $165^{\circ} \mathrm{C}$ (figure 3; red line), and the collection of the crude reaction mixture was started at this time. The crude product was concentrated in vacuo, and the residue was purified by flash column chromatography on silica gel (hexane/EtOAc) to give $\beta$ lactams 6a-s. CAUTION: special precautions must be taken because the hazard associated with the diazocompounds and the ketene derivatives. All work was carried in a well ventilated fumehood, with an automatic shut down of the system in case of an increase of the temperature and pressure over the maximum value set. The spectroscopic data of trans6a, ${ }^{48}$ trans $-6 \mathbf{6},{ }^{6}$ trans $-\mathbf{6 g},{ }^{49}$ trans $-\mathbf{6} \mathbf{i},{ }^{41}$ cis- $\mathbf{6} \mathbf{j},{ }^{50}$ trans $-6 \mathbf{6 m},{ }^{41}$ trans $-6 \mathbf{6},{ }^{51}$ are in accordance with the literature.

1-Benzyl-3-(benzofuran-2-yl)-4-phenylazetidin-2-one. dr trans/cis 92:8. Trans-6b, $61 \% .{ }^{1} \mathrm{H}$ NMR $\left(600 \mathrm{MHz}, \mathrm{CDCl}_{3}\right) \delta 7.52(\mathrm{~d}, J=7.6 \mathrm{~Hz}, 1 \mathrm{H})$, $7.24-7.46(\mathrm{~m}, 12 \mathrm{H}), 7.21(\mathrm{td}, J=7.5,1.0 \mathrm{~Hz}, 1 \mathrm{H}), 6.64(\mathrm{~s}, 1 \mathrm{H}), 5.00(\mathrm{~d}, J=$ $15.1 \mathrm{~Hz}, 1 \mathrm{H}), 4.64(\mathrm{~d}, J=2.4 \mathrm{~Hz}, 1 \mathrm{H}), 4.38(\mathrm{~d}, J=2.3 \mathrm{~Hz}, 1 \mathrm{H}), 3.92(\mathrm{~d}, J=$ $15.2 \mathrm{~Hz}, 1 \mathrm{H}) .{ }^{13} \mathrm{C}$ NMR $\left(150.0 \mathrm{MHz}, \mathrm{CDCl}_{3}\right) \delta 165.5,155.0,150.7,136.6$, $135.1,129.1,128.9,128.8,128.4,128.2,127.8,126.5,124.3,122.9,120.9$ 111.1, 105.2, 60.4, 59.1, 44.9. IR (neat, $\mathrm{cm}^{-1}$ ) 3674, 2988, 1755, 1453, $1252,1076,725$. HRMS $m / z$ calculated for $\mathrm{C}_{24} \mathrm{H}_{20} \mathrm{NO}_{2}[\mathrm{M}+\mathrm{H}]^{+} 354.1494$ found 354.1503 .

\section{Acknowledgment}

The authors would like to acknowledge Dr Aki Tomita and Professor Jonathan M. Goodman for helpful discussions and suggestions. Also, the authors are thankful to the EPSRC (Award Nos. EP/K009494/1, EP/K039520/1 and EP/M004120/1) for financial support.

\section{Supporting Information}

YES

\section{Primary Data}

NO

\section{References}

(1) a) Wolff, L. Justus Liebigs Ann. Chem. 1902, 325, 129. b) Meier, B. H. Angew. Chem. Int. Ed. 1975, 14, 32-43.

(2) Yokozawa, S.; Ohneda, N.; Muramatsu, K.; Okamoto, T.; Odajima, H.; Ikawa, T.; Sugiyama, J.; Fujita, M.; Sawairi, T.; Egami, H.; Hamashima, Y.; Egi, M.; Akai, S. RSC Adv. 2015, 5, 10204-10210.

(3) Morschhäuser, R.; Krull, M.; Kayser, C.; Boberski, C.; Bierbaum, R.; Püschner, P. A.; Glasnov, T. N.; Kappe, C. O. Green Process. Synth. 2012, 1, 281-290.

(4) Kappe, C. O. Chem. Soc. Rev. 2013, 42, 4977-4990.

(5) Tenud, L. Helv. Chim. Acta 1977, 60, 975-977.

(6) Hafner, A.; Ley, S. V. Synlett 2015, 26, 1470-1474.

(7) a) Linder, M. R.; Podlech, J. Org. Lett. 2001, 3, 1849-1851; b) Bandyopadhyay, D.; Banik, B. K. Helv. Chim. Acta 2010, 93, 298301. c) Prieto, P.; Liu, R. Org. Biomol. Chem., 2010, 8, 929-1220.

(8) a) Qi, H.; Li, Z.; Xu, J. Org. Biomol. Chem. 2011, 9, 2702-2714; b) Li, B.; Wang, Y.; Du, D.-M.; Xu, J. J. Org. Chem. 2007, 72, 990-997; c) Jiao, L.; Liang, Y.; Xu J. J. Am. Chem. Soc. 2006, 128, 6060-6069; d) Liang, Y.; Jiao, L.; Zhang, S.; Xu, J. J. Org. Chem. 2005, 70, 334-337; e) Yang, Z.; Xu, J. Tetrahedron Lett. 2012, 53, 786-789.

(9) a) Domingo, L. R.; Rios-Gutierrez, M.; Saez, J. A. RSC Adv. 2015, 5 37119-27129; b) Cossio, F. P.; Arrieta, A.; Sierra, M. A. Acc. Chem. Res. 2008, 41, 925-936; c) Banik, B. K.; Lecea, B.; Arrieta, A.; de Cozar, A.; Cossio, F. P. Angew. Chem. Int. Ed. 2007, 46, 3028-3032; d) Arrieta, A.; Lecea, B.; Cossio, F. P. Top Heterocycl. Chem., 2010, 22, $313-347$.

(10) Pauling, L. Orv. Hetil. 1969, 110, 549-550.

(11) Blanco, F.; Alkorta, I.; Elguero, J. Croat. Chem. Acta 2009, 82, 173183.

(12) Endo-addition pathways have been also analysed for $\mathrm{N}$-methyl and $N$-tert-butylbenzylideneimines $\mathbf{4 b}$ and $\mathbf{4 e}$. Similar to the described $\mathrm{N}$-phenylbenzylideneimine $\mathbf{4 h}$, they were characterized with higher activation barriers. For the 3D structures, see ESI.

(13) Wright, S. W. In Name Reactions for Carbocyclic Ring Formations; Li, J. J., Ed.; John Wiley \& Sons: Hoboken, NJ, 2010; pp 45-69.

(14) Kirmse, W.; Rondan, N. G.; Houk, K. N. J. Am. Chem. Soc. 1984, 106, 7989-7991.

(15) IUPAC. Compendium of Chemical Terminology, 2nd ed. (the "Gold Book"). Compiled by A. D. McNaught and A. Wilkinson. Blackwell Scientific Publications, Oxford (1997). XML on-line corrected version: http://goldbook.iupac.org (2006) created by Nic, M.; Jirat, J.; Kosata, B.; updates compiled by A. Jenkins. ISBN 0 9678550-9-8

(16) Harvey, M. J.; Mason, N. J.; Rzepa, H. S. J. Chem. Inf. Model. 2014 54, 2627-2635.

(17) a) Gillet, A.; Sanner, M.; Stoffler, D.; Goodsell, D.; Olson, A. IEEE Visualization 2004, 235-242; b) Nunez, M.; Quiros, R.; Nunez, I.; Carda, J. B.; Camahort, E. 5th WSEAS / IASME (EE'08), 2008, 271 277 c) http://elements4d.daqri.com/\#lessons; d) http://sponholtzproductions.com/Product_Reviews.html.

(18) Acronyms: Quick Response (QR) and Uniform Resource Locator (URL).

(19) https://developer.mozilla.org/en/docs/Web/API/MediaStream

(20) Hamming, R. W. The Bell System Technical Journal 1950, 29, $147-$ 160 . 
(21) [a) J.-D. Chai, M. Head-Gordon Phys. Chem. Chem. Phys. 2008, 10, $6615-6620$; b) R. A. Kendall, T. H. Jr. Dunning, R. J. Harrison J Chem. Phys. 1992, 96, 6796-806.

(22) For benchmarking studies showing high accuracy and applicability of the $\omega \mathrm{B} 97 \mathrm{xD} / \mathrm{cc}-\mathrm{PVTZ} / / \omega \mathrm{B} 97 \mathrm{xD} / \mathrm{cc}-\mathrm{PVDZ}$ method to organic transformations, see: a) S. Schenker, C. Schneider, S. B. Tsogoeva, T. Clark J. Chem. Theory Comput. 2011, 7, 3586-3595. b) M. A. Kabeshov, O. Kysilka, L. Rulíšek, Y. V. Suleimanov, M. Bella, A. V. Malkov, P. Kočovský Chem. Eur. J., 2015, 21, 1202612033.

(23) Acetonitrile $(\varepsilon=35.688)$ was used as a solvent; for more details see: A. V. Marenich, C. J. Cramer, D. G. Truhlar J. Phys. Chem. B 2009, 113, 6378-6396.

(24) Gaussian 09, Revision D.01, M. J. Frisch, G. W. Trucks, H. B. Schlegel, G. E. Scuseria, M. A. Robb, J. R. Cheeseman, G. Scalmani, V. Barone, B. Mennucci, G. A. Petersson, H. Nakatsuji, M. Caricato, X. Li, H. P. Hratchian, A. F. Izmaylov, J. Bloino, G. Zheng, J. L. Sonnenberg, M. Hada, M. Ehara, K. Toyota, R. Fukuda, J. Hasegawa, M. Ishida, T. Nakajima, Y. Honda, O. Kitao, H. Nakai, T. Vreven, J. A. Montgomery, Jr., J. E. Peralta, F. Ogliaro, M. Bearpark, J. J. Heyd, E. Brothers, K. N. Kudin, V. N. Staroverov, T. Keith, R. Kobayashi, J. Normand, K. Raghavachari, A. Rendell, J. C. Burant, S. S. Iyengar, J. Tomasi, M. Cossi, N. Rega, J. M. Millam, M. Klene, J. E. Knox, J. B. Cross, V. Bakken, C. Adamo, J. Jaramillo, R. Gomperts, R. E. Stratmann, O. Yazyev, A. J. Austin, R. Cammi, C. Pomelli, J. W. Ochterski, R. L. Martin, K. Morokuma, V. G. Zakrzewski, G. A. Voth, P. Salvador, J. J. Dannenberg, S. Dapprich, A. D. Daniels, O. Farkas, J. B. Foresman, J. V. Ortiz, J. Cioslowski, and D. J. Fox, Gaussian, Inc., Wallingford CT, 2013.

(25) The SMD intrinsic atomic Coulomb radii were used as implemented in NWChem software.

(26) http://www.nwchem-sw.org/index.php/Release65:SMD_Model.

(27) http://en.wikipedia.org/wiki/CPK coloring

(28) a) M. Tarini, P. Cignoni, C. Montani, IEEE Trans. Vis. Comput Graph. 2006, 12, 1237-1244. b) A. S. Rose, P. W. Hildebrand Nucleic Acids Res. 2015, 1, 1-4. For more details, see: http://proteinformatics.charite.de/ngl/html/ngl.html. c) N. Rego, D. Koes Bioinformatics 2014, 8, 1322-1324. For more details, see: http://3dmol.csb.pitt.edu/index.html. d) F Mwalongo, M. Krone, M. Becher, G. Reina, T. Ertl in Proceeding Web3D '15. Proceeding of the $20^{\text {th }}$ international conference on $3 \mathrm{D}$ web technology, pp. 115-122.
(29) https://developer.mozilla.org/en/docs/Web/JavaScript/Reference/Gl obal_Objects/JSON.

(30) Revision 73. For more details, see: http://threejs.org/.

(31) a) S. Garrido-Jurado, R. Muñoz-Salinas, F. J. Madrid-Cuevas, M. J. Marín-Jiménez Pattern Recognition, 2014, 47, 2280-2292. https://github.com/jcmellado/js-aruco ; b) http://opencv.org/.

(32) http://cg.skeelogy.com/skarfjs/.

(33) T. Toma, J. Shimokawa, T. Fukuyama Org. Lett. 2007, 9, 10-12.

(34) R. J. Sharpe, J. T. Malinowski, J. S Johnson J. Am. Chem. Soc. 2013, 135, 17990-17998.

(35) A. Lancou, H. Haroun, U. K. Kundu, F. Legros, N. Zimmermann, M. Mathe-Allainmat, J. Lebreton, G. Dujardin, C. Gaulon-Nourry, P. Gosselin Tetrahedron 2012, 68, 9652-9657.

(36) V. A. Nikolaev, P. Y. Utkin, I. K. Korobitsyna Zh. Org. Khim. 1989, 25, 1176-1179.

(37) A. J. A. Watson, R. J. Wakeham, A. C. Maxwell, J. M. J. Williams Tetrahedron 2014, 70, 3683-3690.

(38) H. Lundberg, F. Tinnis, H. Adolfsson Synlett 2012, 23, 2201-2204.

(39) P. Starkov, T. D. Sheppard Org. Biomol. Chem. 2011, 9, 1320-1323.

(40) S. C. Ghosh, S. H. Hong European J. Org. Chem. 2010, 4266-4270.

(41) B. Ramalingam, A. M .Seayad, L. Chuanzhao, M. Garland, K. Yoshinaga, M. Wadamoto, T. Nagata, C. L. L. Chai Adv. Synth. Catal. 2010, 352, 2153-2158.

(42) S. Perrone, A. Salomone, A. Caroli, A. Falcicchio, C. Citti,G. Cannazza, L. Troisi European J. Org. Chem. 2014, 5932-5938.

(43) W. M. Shu, J. R. Ma, K. L. Zheng, H. Y. Sun, M. Wang, Y. Yang, A. X. Wu Tetrahedron 2014, 70, 9321-9329.

(44) S. Schoumacker, O. Hamelin, S. Téti, J. Pécaut, M. Fontecave J. Org. Chem. 2005, 70, 301-308.

(45) L. Troisi, L. Ronzini, C. Granito, L. D. Vitis, E. Pindinelli Tetrahedron 2006, 62, 1564-1574.

(46) J. S. Bennett, K. L. Charles, M. R. Miner, C. F. Heuberger, E. J. Spina, M. F. Bartels, T. Foreman Green Chem. 2009, 11, 166-168.

(47) L. R. Knöpke, N. Nemati, A. Köckritz, A. Brückner, U. Bentrup ChemCatChem 2010, 2, 273-280.

(48) I. Kim, S. W. Roh, D. G. Lee, C. Lee Org. Lett. 2014, 16, 2482-2485.

(49) Z. Zhang, Y. Liu,L. Ling, Y. Li, Y. Dong, M. Gong, X. Zhao, Y. Zhang, J. Wang J. Am. Chem. Soc. 2011, 133, 4330-4341.

(50) L. Troisi, E. Pindinelli, V. Strusi, P. Trinchera Tetrahedron Asymmetry 2009, 20, 368-374.

(51) A. K. Bose, H. P. S. Chawla, B. Dayal, D. A. Foleys Org. Magn. Reson. 1976, 8, 151-154. 